\title{
COLABORAM NESTE NUMERO
}

Francisco das Chagas Meln - Ex-Técnico de Administração do D.A.S.P. e exAssistente de Orçamento do mesmo Departamento. Exerceu a função de Assessor T'écnico do Diretor da Divisão de Seleção e Aperfeiçoamento do D.A.S.P. e a de membro da Comissão encarreSada de examinar prestação de contas riferentes aos Planos de Obras relativos aos anos de 1944-46. Atualmente, é Assessor Legislativo do Quadro de Pessoal do Senado Federal.

Vicente Ferrer Correia Lima - Ex-Assistente de Seleção do D.A.S.P. Assistente de Administração do Ministério da Aqricultura. Atualmente à disposição da NOVACAP.

Tomás de Villanova M. Lopes - Técnico de Administração do Q.P. do D.A.S.P.; ex-Diretor da Divisão de Seleção e Aperfeiçoamento dêste Departamento; ex-Diretor do Serviço de Documentação. Professor dos Cursos de Administração do D.A.S.P. Atualmente, à disposição da Casa da Moeda.

Atrilio Joffily Pereira da Costa - Inspetor-auxiliar de Obras no I.P.A.S.E. Colaborador dos Diários Associacios, da Revista do Departamento Nacional do Café e de vários órgãos de imprensa.

Fenelon Silva - Bacharel em Direito. ExAssistente de Organização do D.A.S.P.

- Foi chefe da Seção de Organização do Serviço de Organização e Métodos da Divisão de Orçamento dêste Departamento. Foi representante do D.A.S.P. na Comissão Executiva no Estado do Piaui para colaborar na solução de problemas relativos à organização administrativa do referido Estado. Professor da cadeira de Organização de Serviços e Diretio Admi- nistrativo dos Cursos de Administração do D.A.S.P.

Maria Amélia Porto Migueis - Foi Bibliotecária-auxiliar do quadro do D.A.S.P. Possui curso de aperfeiçoamento de Tecnologia de Encadernação e Douração do Departamento de Imprensa Nacional. Exsubstituta do chefe da Biblioteca do Serviço de Documentação dêste Departamento. Exerce atualmente o cargo de Bibliotecário do quadro do D.A.S.P.

Henry Puget - Conselheiro de Estado da França. Professor do Instituto de Estudos Políticos; Diretor da Universidade de Paris e Presidente da Comissão Cientifica do Instituto Internacional de Ciências Administrativas.

Celso Peçanha - Deputado Federal pelo Estado do Rio.

VAsco Ribeiro da Costa - Capitão do Exército servindo, presentemente, na Escola de Comando e Estado Maior do Exército. Economista pela Faculdade de $\mathrm{Ci}$ ências Politicas e Econômicas do Rio de Janeiro. Autor de «Considerações e Idéias sôbre o problema econômico $\mathrm{Na}$ cional», trabalho editado pelo Serviço de Documentação do D.A.S.P. Autor de vários trabalhos publicados nas Revistas «Defesa Nacional» e «Clube Militar».

Nelson Nascimento Santos - Engenheiro do Q.P. do Ministério da Fazenda, lotado no Serviço do Patrimônio da União. Possui trabalhos sôbre avaliações do terreno de imóveis e novo processo de cálculo de áreas levantadas topogràficamente, publicados em doze revistas do Clube de Engenharia do Rio (sob os ns. $167,169,171,174,178,185,189$, 191, 192, 193, 194 e 202). 